\title{
The occurrence of carboxymycobactin, the siderophore of pathogenic mycobacteria, as a second extracellular siderophore in Mycobacterium smegmatis
}

\author{
Colin Ratledge and Maureen Ewing \\ Author for correspondence: Colin Ratledge. Tel: +44 1482 465243. Fax: + 441482 465458. e-mail: \\ c.ratledge@appbiol.hull.ac.uk
}

Department of Applied Biology, University of Hull, Hull HU6 7RX, UK

\begin{abstract}
Carboxymycobactin, in which the usual intracellular mycobactin siderophore is modified by possession of a carboxylic acid group, has been isolated as a second extracellular siderophore from culture filtrates of Mycobacterium smegmatis grown under iron-deficient conditions. (The primary siderophore is an exochelin which is a trihydroxamate, pentapeptide derivative.) There may be up to 12 similar molecules produced with differing chain lengths that can be recognized by HPLC or HPTLC. The amount of carboxymycobactin is about 20 times higher when cultures are grown with glycerol instead of glucose. Formation is maximal with an initial pH of the medium of about 8.4. The proportion of carboxymycobactin to the total siderophores produced - mainly exochelins - is maximally $10 \%$ (usually $10-25 \mu \mathrm{g} \mathrm{ml}^{-1}$ ). Formation of both extracellular siderophores (exochelin and carboxymycobactin) and of the intracellular mycobactin is maximal at the same initial concentration of iron added to the medium, 0.05-0.1 $\mu \mathrm{g} \mathrm{Fe} \mathrm{ml}^{-1}$, though exochelin is synthesized $24 \mathrm{~h}$ in advance of both carboxymycobactin and mycobactin.
\end{abstract}

Keywords: carboxymycobactin, exochelin, iron, Mycobacterium smegmatis, mycobactin

\section{INTRODUCTION}

Iron solubilization and uptake is an essential prerequisite for the growth of most cells. In mycobacteria there are both intra- and extracellular iron-binding compounds whose synthesis is increased by iron deprivation (see Wheeler \& Ratledge, 1994). These are, respectively, the mycobactins (see Snow, 1970) and the exochelins (Macham \& Ratledge, 1975). Although it has long been known (Macham et al., 1975) that the exochelins were of two types - water-soluble, non-extractable entities found in the saprophytic species and chloroform-extractable materials found in the supernatant cultures of pathogens such as Mycobacterium tuberculosis, $M$. avium and $M$. bovis $\mathrm{BCG}$ - it is only recently that the first structures of representative siderophores of both these two types have been published.

The exochelin from $M$. smegmatis is of the first type and is a pentapeptide based on three $N$-hydroxyornithinyl residues: $\quad N$-( $\delta N$-formyl- $\delta N$-hydroxyl-D-ornithinyl)- $\beta$ alaninyl- $\delta N$-hydroxy-D-ornithinyl-D-allo-threoninyl- $\delta N$ hydroxy-L-ornithine (Sharman et al., 1995a). The structure of another but a different peptido-exochelin from $M$. neoaurum has also been recently published, showing it to be a hexapeptide that involves a novel $\beta$-hydroxyhistidinyl residue and two $N$-hydroxyornithinyl residues (Sharman et al., 1995b).

The structure of the chloroform-extractable exochelin from M. avium has also been elucidated (Lane et al., 1995) but, unlike the siderophores from the non-pathogens, this molecule closely resembles the structure of mycobactin itself, which is characterized by the presence of an aromatic moiety - usually salicylic acid - and a $\mathrm{C}_{18}-\mathrm{C}_{20}$ alkyl or alkenyl side-chain that confers lipid-like properties on the molecule. Mycobactin is located wholly intracellularly. The extracellular counterpart to mycobactin possesses the same nuclear structure as mycobactin but has a short carboxy(acyl) side-chain in place of the long alkyl or alkenyl chain, thereby diminishing its lipoidal character and enabling the molecule to be released from the cell. To avoid confusion with the water-soluble, peptido-exochelins, the name 'carboxymycobactin' has been suggested for these siderophores (Lane et al., 1995). A methyl ester of carboxymycobactin has independently been reported to occur as the siderophore in $M$. tuberculosis (Gobin et al., 1995) though our own work would suggest 
Table 1. Formation of exochelin (as $90-95 \%$ of total iron-binding compounds), and carboxymycobactin (the two extracellular siderophores) and mycobactin (the intracellular siderophore) in $M$. smegmatis

Cultures were grown iron-deficiently for $7 \mathrm{~d}$ on glucose or glycerol (at $10 \mathrm{~g}^{-1}$ )/asparagine medium $(6 \times 100 \mathrm{ml})$ at $\mathrm{pH} 7 \cdot 0$. Total iron-binding compounds and carboxymycobactin were determined in pooled supernatants, and mycobactin was determined in pooled cells from the six cultures.

\begin{tabular}{|c|c|c|}
\hline & \multicolumn{2}{|c|}{$\begin{array}{l}\text { Carbon source in } \\
\text { growth medium: }\end{array}$} \\
\hline & Glucose & Glycerol \\
\hline $\begin{array}{l}\text { Total iron-binding compounds in } \\
\text { supernatant* (mg per } 600 \mathrm{ml} \text { ) }\end{array}$ & 78 & 90 \\
\hline Carboxymycobactint (mg per $600 \mathrm{ml}$ ) & $0 \cdot 05$ & $1 \cdot 04$ \\
\hline Mycobactin $\ddagger$ (mg total) & 30 & $32 \cdot 8$ \\
\hline
\end{tabular}

* Calculated from a notional $A_{\mathbf{4 2 0}}^{1 \%}$ of $17 \cdot 4$ (see Methods).

† Calculated from an estimated $A_{450}^{1 \%}$ of 48 .

$\ddagger$ Calculated from an estimated $A_{450}^{1 \%}$ of 43 .

that the unesterified, free acid carboxy(acyl)mycobactin is the major material compound being produced.

At first sight, therefore, the following statements would seem valid: (1) all mycobacteria, with one or two exceptions (e.g. M. vaccae and $M$. paratuberculosis), contain mycobactin as an intracellular siderophore; (2) pathogenic mycobacteria produce an extracellular chloroform-soluble carboxymycobactin as the putative iron-scavenging and transporting agent; and (3) non-pathogenic mycobacteria produce water-soluble, peptido-siderophores for which the trivial name 'exochelin' is still retained.

We now report the occurrence of a carboxymycobactin in the culture filtrates of the non-pathogen $M$. smegmatis, along with exochelin but at only about $5-10 \%$ of the total iron-sequestering capacity. The confinement of the carboxymycobactins to pathogenic species, and thus their possible relevance to mycobacterial virulence, is therefore not tenable. Iron acquisition in mycobacteria is thus a more complex process than has previously been thought.

\section{METHODS}

Organism and growth. Mycobacterium smegmatis NCIMB 8548 was grown in $250 \mathrm{ml}$ conical flasks, pretreated to remove trace metals, containing $100 \mathrm{ml}$ medium which consisted of glycerol or glucose, $10 \mathrm{~g} ; \mathrm{KH}_{2} \mathrm{PO}_{4}, 5 \mathrm{~g}$; L-asparagine, $5 \mathrm{~g}$; $\mathrm{pH}$ to $7 \cdot 0$ or alternative value with $\mathrm{KOH}$. Medium was autoclaved with $2 \%$ $(\mathrm{w} / \mathrm{v})$ aluminium oxide to remove trace metals and dispensed as previously described (Ratledge \& Hall, 1971). When glucose was used as carbon source, this was sterilized separately (Sharman et al., 1995a). Medium was supplemented with

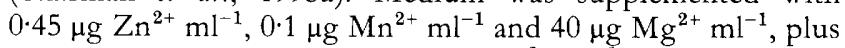
for iron-deficient growth $0.04 \mu \mathrm{g} \mathrm{Fe}^{2+} \mathrm{ml}^{-1}$ and for ironsufficient growth $2 \cdot 0 \mu \mathrm{g} \mathrm{Fe}{ }^{2+} \mathrm{ml}^{-1}$. Cultures were inoculated with $1 \mathrm{ml}$ of a 5 - to 7-d-old culture grown on iron-deficient medium and were incubated with shaking at $37^{\circ} \mathrm{C}$ for 6 or $7 \mathrm{~d}$. Growth was measured by direct weighing of dried cells.

\section{Isolation of siderophores}

Total iron-binding compounds. Cultures were centrifuged $(10000 \mathrm{~g}$ for $20 \mathrm{~min}$ ) and the absorbance of the solution read at $420 \mathrm{~nm}$ to give background values for non-iron-binding coloured material. The $\mathrm{pH}$ was then adjusted to 3.5 with $\mathrm{H}_{2} \mathrm{SO}_{4}$ and the absorbance re-read. (As the second value was usually unchanged from the previous reading, only the latter was normally measured.) $\mathrm{FeCl}_{3}(10 \%, \mathrm{w} / \mathrm{v}$, in ethanol) was added dropwise to the solution until a precipitate (ferric phosphate) began to form; the solution was stirred for $60 \mathrm{~min}$, centrifuged to remove the precipitate and the absorbance of the supernatant then re-determined at $420 \mathrm{~nm}$. The total iron-binding compounds were determined from an $A_{420}^{1 \%}$ value of $17 \cdot 4$ minus the background value, assuming that the total iron-binding capacity of the medium was due to exochelins and carboxymycobactin at a notional $95: 5(\mathrm{w} / \mathrm{w})$ ratio.

Carboxymycobactins. The above iron-saturated supernatant solution was extracted with chloroform $(3 \times 0.5$ vol. $)$. The chloroform extract was washed twice with deionized water, dried over anhydrous $\mathrm{MgSO}_{4}$, evaporated under reduced pressure and the residue taken up in about $10 \mathrm{ml}$ ethanol. This was then passed through a $40 \times 2.5 \mathrm{~cm}$ column of Sephadex LH20 in ethanol and eluted with ethanol at $2.5 \mathrm{ml} \mathrm{min}^{-1}$. The main fraction was collected (after approx. $300 \mathrm{ml}$ ), the solvent removed by rotary evaporation and the final residue dissolved in ethanol for subsequent analysis. Carboxymycobactin was estimated from its absorbance in ethanol at $450 \mathrm{~nm}$ using a value of $A_{450}^{1 \%}=48$ based on the corresponding value for the higher molecular weight mycobactin (see below).

Exochelins. The chloroform-extracted supernatant was readjusted to $\mathrm{pH} 7$ with $\mathrm{NaOH}$ and the residual chloroform was removed by rotary evaporation. Exochelins were then recovered from the aqueous solution by two-step cation-exchange chromatography following the procedure of Sharman et al. (1995a). Exochelins were estimated from an $A_{420}^{1 \%}$ value of 15.8 in water for the major component (Sharman et al., 1995a).

Mycobactin. Mycobactin was extracted from freshly harvested cells by suspending them in ethanol and following the procedure of Messenger \& Ratledge (1986) up to its transfer into chloroform and back into ethanol. Mycobactin was estimated from its $A_{450}^{1 \%}$ value of 43 in ethanol.

Chromatographic analyses. Thin-layer chromatography was carried out on $100 \times 100 \mathrm{~mm}$ glass plates with high-performance thin layers (HPTLC) of silica gel G (Whatman, type HP-K) using the solvents as given in Table 2 . The red carboxymycobactins and mycobactins could be easily seen, but visualization was enhanced by viewing the plate under UV light $(257 \mathrm{~nm})$ and holding the plate above a bright white sheet of paper. Ordinary silica gel $G$ plates do not resolve the individual carboxymycobactins even under the best conditions.

HPLC of carboxymycobactin was carried out essentially as described by Lane et al. (1995) using a Lichrosorb RP-18, $10 \mu$, reversed-phase column, $250 \times 3.2 \mathrm{~mm}$, with a gradient of water/methanol $(50: 50, \mathrm{v} / \mathrm{v})$ to water/methanol $(30: 70, \mathrm{v} / \mathrm{v})$ over $20 \mathrm{~min}$ then holding at this concentration for a further $20 \mathrm{~min}$. The elution rate was $0.5 \mathrm{ml} \mathrm{min} \mathrm{m}^{-1}$ and the eluate was monitored continuously at $440 \mathrm{~nm}$.

$\mathrm{UV} /$ visible spectra were recorded in a double-beam spectrophotometer (Unicam SP1800) set at its slowest rate of scan $\left(0 \cdot 2 \mathrm{~nm} \mathrm{~s}^{-1}\right)$. 


\section{RESULTS}

For the original isolation and characterization of exochelin from M. smegmatis (see Sharman et al., 1995a), cultures had been grown with $10 \mathrm{~g}$ glucose $\mathrm{l}^{-1}$ instead of the more usual glycerol in order to avoid problems with residual substrate during the isolation procedure. When such cultures were examined for the presence of carboxymycobactin, as a chloroform-extractable extracellular siderophore, only very small amounts of material were seen (Table 1). However, when cultures were grown irondeficiently with glycerol the amount of chloroformsoluble siderophore that was now produced was increased 20 -fold (Table 1) although the total amount was still only about $1 \%$ of the total extracellular iron-sequestering compounds in the culture filtrates. The procedure used to assess carboxymycobactin and exochelin would not have measured the presence of salicylic acid, which occurs in culture filtrates of $M$. smegmatis (cf. Ratledge \& Winder, 1962), as ferri-salicylate does not form in the presence of

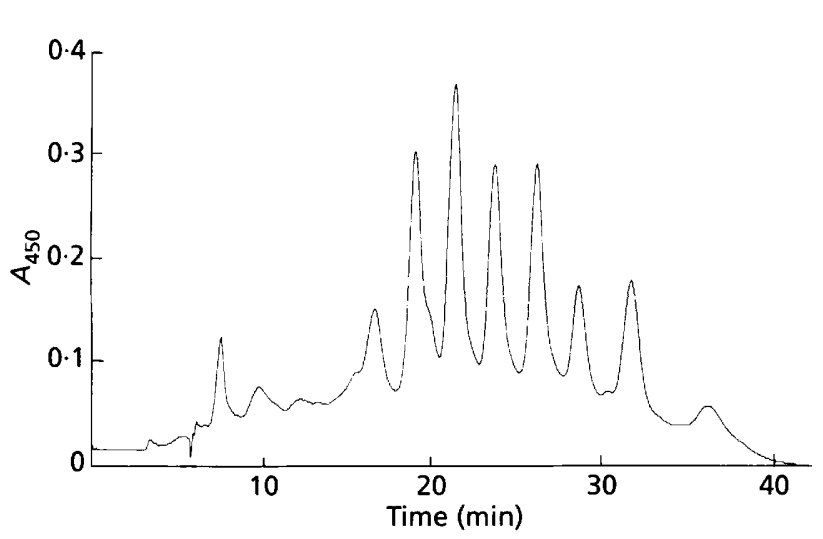

Fig. 1. HPLC of carboxymycobactins from culture supernatant of $M$. smegmatis grown for $6 \mathrm{~d}$ on iron-deficient glycerol/asparagine medium, $\mathrm{pH} 7 \cdot 4$. Carboxymycobactins were extracted at $\mathrm{pH} 3.5$ with chloroform and partially purified by gel filtration through Sephadex LH20. See Methods for details.

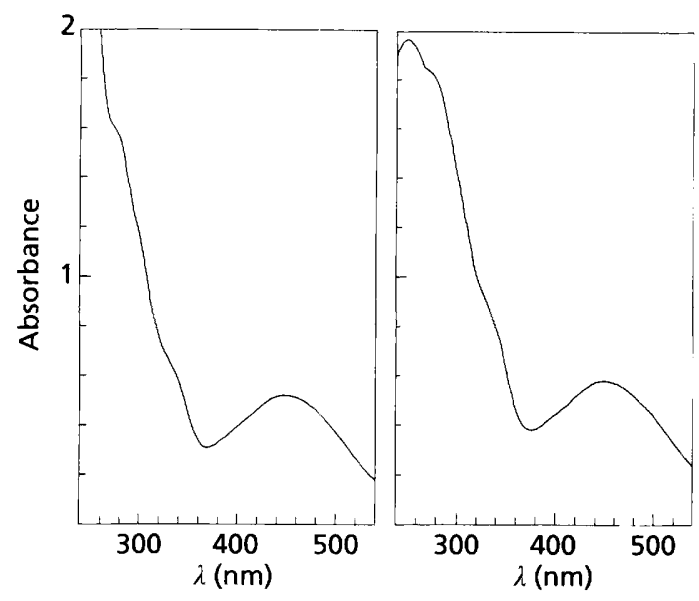

Fig. 2. UV/visible spectrum of (a) carboxymycobactin (after HPLC purification) and (b) mycobactin as purified to $100 \%$ by the procedure of Messenger \& Ratledge (1986), both from $M$. smegmatis grown iron-deficiently on glycerol/asparagine medium, $\mathrm{pH} 7.0$. Both spectra show the same $\lambda_{\max }$ at $445 \mathrm{~nm}$ with shoulders at $338-340$ and at $274-276 \mathrm{~nm}$.

phosphate ions. It also should be pointed out that although the amount of total iron-binding material in the iron-deficient medium was relatively high (about $100 \mu \mathrm{g} \mathrm{ml}^{-1}$ ), the major exochelin which has been isolated and characterized (Sharman et al., 1995a) probably represents about $25-35 \%$ of this material; the remaining siderophores are probably structural variations on the major exochelin (see Macham et al., 1977).

The carboxymycobactins were analysed by HPLC (Fig. 1) and HPTLC (Table 2). The multiplicity of components separated by both systems is attributed to there being a homologous series of molecules analogous to those already identified for $M$. avium, $M$. tuberculosis and $M$. bovis (Lane et al., 1995) and is probably due to the variations in the alkyl chain length and the presence of a double bond in some chains.

Table 2. Separation of carboxymycobactins and mycobactins from $M$. smegmatis by HPTLC

See Methods for details. $R_{F}$ values in bold are main components.

\begin{tabular}{|c|c|c|c|}
\hline & \multicolumn{3}{|c|}{$R_{F}$ values in solvent system*: } \\
\hline & I & II & III \\
\hline Carboxymycobactin & $0 \cdot 23,0 \cdot 25,0 \cdot 28, \mathbf{0} \cdot \mathbf{3 2}, \mathbf{0} \cdot \mathbf{3 4}, \mathbf{0} \cdot \mathbf{3 7}$ & $0.13 \rightarrow 0 \cdot 16 \dagger$ & 0.03 \\
\hline Mycobactin & $0.50,0.52,0.64$ & $0 \cdot 28, \mathbf{0} \cdot \mathbf{3 8}$ & 0.92 \\
\hline
\end{tabular}

* Solvent systems: I, ethanol/cyclohexane/water/ethyl acetate/acetic acid $(5: 25: 2 \cdot 5: 35: 5$, by vol.). (The content of water is critical; the mobile phase must be fully saturated with water.) II, light petroleum (b.p. $\left.40-60^{\circ} \mathrm{C}\right) /$ butan-1-ol/ethyl acetate $(2: 3: 3$, by vol.). III, as I but with triethanolamine in place of acetic acid.

$\uparrow$ Merged compounds not resolved. 
Table 3. Changes in production of exochelin and carboxymycobactin with the initial $\mathrm{pH}$ of the culture medium

M. smegmatis was grown in glycerol/asparagine medium (with $\mathrm{KH}_{2} \mathrm{PO}_{4}$ increased from $5 \mathrm{~g} \mathrm{l}^{-1}$ to $9 \mathrm{~g} \mathrm{l}^{-1}$ ) under iron-deficient conditions for $4 \mathrm{~d}$. Exochelin and carboxymycobactin were determined by the absorbances given in Table 1 .

\begin{tabular}{|cccc|}
\hline \multicolumn{2}{|c}{$\mathbf{p H}$} & $\begin{array}{c}\text { Exochelin } \\
\text { (mg per 100 } \mathbf{~ m l})\end{array}$ & $\begin{array}{c}\text { Carboxymycobactin } \\
(\mathbf{m g} \text { per 100 } \mathbf{~ m l})\end{array}$ \\
\cline { 1 - 2 } Initial & Final & & \\
\hline $7 \cdot 0$ & $8 \cdot 8$ & $30 \cdot 0$ & $1 \cdot 0$ \\
$7 \cdot 6$ & $8 \cdot 9$ & $47 \cdot 8$ & $1 \cdot 8$ \\
$8 \cdot 0$ & $9 \cdot 2$ & $44 \cdot 0$ & $2 \cdot 9$ \\
$8 \cdot 4$ & $9 \cdot 3$ & $33 \cdot 6$ & $3 \cdot 1$ \\
$9 \cdot 3$ & $9 \cdot 1$ & $60 \cdot 6$ & $2 \cdot 7$ \\
\hline
\end{tabular}

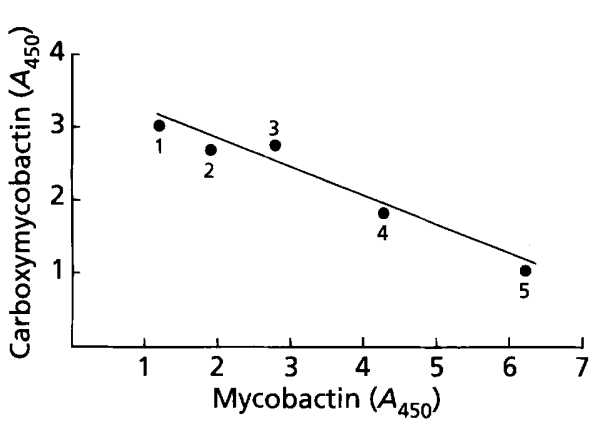

Fig. 3. Relationship between carboxymycobactin and mycobactin formation in cultures of $M$. smegmatis grown iron-deficiently for $6 \mathrm{~d}$ with different initial $\mathrm{pH}$ values: points 1 and 2, $\mathrm{pH} 8.4$; points 3 and 4, pH 8.0; point 5, pH 7.6. Carboxymycobactin, as chloroform-extracted culture supernatant material, values as $A_{450}$ in $5 \mathrm{ml}$ ethanol; mycobactin, as ethanol-extracted cell material, values as $A_{450}$ in $50 \mathrm{ml}$ ethanol.
Extraction of the carboxymycobactins from the culture filtrates with chloroform was considerably more efficient at $\mathrm{pH} 3-3.5$ than at $\mathrm{pH} 7$, which was strongly suggestive of the molecule having a carboxylic acid group. This is supported by the very low $R_{F}$ value of the triethanolamine derivative upon HPTLC compared to mycobactin itself (solvent III in Table 2) and the higher $R_{F}$ value (i.e. the more soluble form) in the acidic solvent (no. I, Table 2). The UV spectra of carboxymycobactin and mycobactin were similar (Fig. 2), suggesting a common nuclear structure. This was then confirmed by ${ }^{1} \mathrm{H}-\mathrm{NMR}$ (D. F. Ewing, unpublished work) though the exact position of the carboxylic acid group on the mycobactin remains to be determined. The available evidence indicates that this chloroform-soluble siderophore from $M$. smegmatis is the equivalent or near-equivalent structure to that proposed for the carboxymycobactin from $M$. avium (Lane et al., 1995); evidence for a similar siderophore in M. tuberculosis has been provided (Gobin et al., 1995).

The production of carboxymycobactin was dependent upon the $\mathrm{pH}$ of the culture medium, with substantially increased amounts being produced at over $\mathrm{pH} 8$. An initial $\mathrm{pH}$ of 8 or 8.4 gave the highest amounts of carboxymycobactin (Table 3 ). When the results from a number of experiments were evaluated and the amount of carboxymycobactin produced compared to the amount of mycobactin formed, there was an apparent inverse correlation between the formation of the two compounds (Fig. 3). This could suggest that there is a common precursor of both compounds and when the formation of carboxymycobactin increases this decreases the amount of precursor that can be converted into mycobactin.

The production of carboxymycobactin was considerably influenced by the iron content of the medium (Table 4). As has been found previously with production of other siderophores, including exochelin and mycobactin, at the lowest iron concentration very little siderophore(s) may

Table 4. Formation of exochelin, carboxymycobactin and mycobactin after growth of $M$. smegmatis with different concentrations of iron

Cultures were grown for $5 \mathrm{~d}$ on glycerol/asparagine medium $(4 \times 100 \mathrm{ml})$ at $\mathrm{pH} 8.4$ with the concentrations of iron indicated. Exochelin, carboxymycobactin and mycobactin were determined by the absorbances given in Table 1. Mycobactin was determined in pooled cells from the four cultures.

\begin{tabular}{|c|c|c|c|c|}
\hline $\begin{array}{l}\text { Iron added } \\
\left(\mu \mathrm{g} \mathrm{ml}^{-1}\right)\end{array}$ & $\begin{array}{c}\text { Exochelin } \\
\text { (mg per } 100 \mathrm{ml})\end{array}$ & $\begin{array}{l}\text { Carboxymycobactin } \\
(\mathrm{mg} \text { per } 100 \mathrm{ml})\end{array}$ & $\begin{array}{l}\text { Mycobactin } \\
\text { (mg total) }\end{array}$ & $\begin{array}{c}\text { Cell dry wt } \\
\text { (g per } 400 \mathrm{ml} \text { ) }\end{array}$ \\
\hline 0 & $5 \cdot 6$ & 0.5 & $5 \cdot 0$ & 0.228 \\
\hline 0.005 & $17 \cdot 8$ & 1.6 & $8 \cdot 9$ & 0.627 \\
\hline 0.01 & $21 \cdot 9$ & $2 \cdot 1$ & $9 \cdot 3$ & 0.733 \\
\hline 0.03 & $27 \cdot 7$ & $1 \cdot 7$ & $22 \cdot 4$ & 1.97 \\
\hline 0.05 & $32 \cdot 5$ & $2 \cdot 5$ & $33 \cdot 2$ & $2 \cdot 20$ \\
\hline 0.075 & $32 \cdot 7$ & $2 \cdot 5$ & $24 \cdot 9$ & $2 \cdot 39$ \\
\hline $0 \cdot 1$ & $32 \cdot 6$ & $1 \cdot 8$ & $29 \cdot 5$ & $3 \cdot 17$ \\
\hline 0.25 & $31 \cdot 4$ & $2 \cdot 2$ & $34 \cdot 8$ & $3 \cdot 17$ \\
\hline 0.5 & $12 \cdot 0$ & $1 \cdot 2$ & 5.9 & $3 \cdot 24$ \\
\hline $1 \cdot 0$ & $7 \cdot 5$ & 0.5 & $2 \cdot 6$ & 3.52 \\
\hline
\end{tabular}



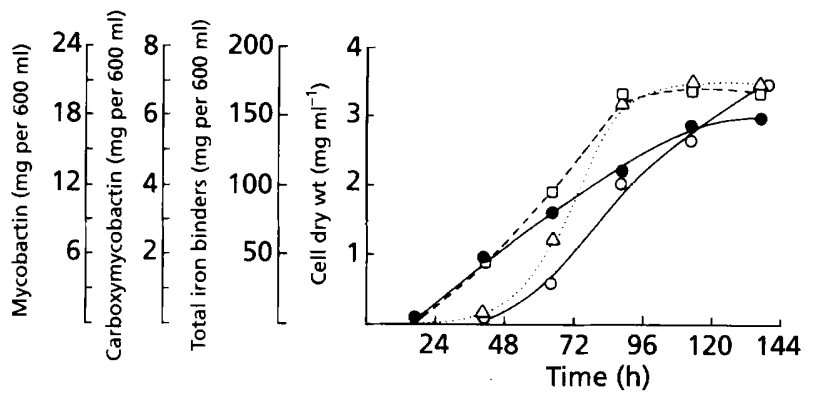

Fig. 4. Time course of production of exochelin (as 90-95\% of total extracellular binding compounds) $(\square)$, carboxymycobactin $(\triangle)$ and mycobactin $(O)$ with growth of $M$. smegmatis (O) under iron-deficient conditions. Each assay was carried out on $6 \times 100 \mathrm{ml}$ shake-flask cultures.

be formed. Formation of exochelin (as total iron-binding compound), carboxymycobactin and mycobactin [as $\mu \mathrm{g}$ (mg dry wt $)^{-1}$ ] was maximal at the same concentration of iron added $\left(0.05-0.075 \mu \mathrm{g} \mathrm{Fe} \mathrm{ml}^{-1}\right)$. Above $1.0 \mu \mathrm{g} \mathrm{Fe} \mathrm{ml} l^{-1}$ formation of all three siderophores decreased. There was no evidence to suggest that the exochelins (as the main component of the total ironbinding compounds) had a different response to iron deficiency than either carboxymycobactin or mycobactin itself. However, the time courses of appearance of the three siderophores were different (Fig. 4). Exochelin could be detected at the earliest time of sampling (16 h) when growth had scarcely begun, but carboxymycobactin and mycobactin could not be detected until after $40 \mathrm{~h}$ growth and did not become significant until $64 \mathrm{~h}$.

\section{DISCUSSION}

Although the amount of carboxymycobactin produced by M. smegmatis makes it a minor siderophore component, which rarely exceeds $10 \%$ of the total iron-binding capacity of spent culture media and is more normally about $5 \%$ of the total, its presence indicates the wider distribution of this type of molecule than previously thought. Hitherto, the chloroform-soluble exochelins, now known to be mycobactin derivatives and accordingly termed 'carboxymycobactins' (Lane et al., 1995), have been considered to be confined to the ' $M$. tuberculosis group' (Wheeler \& Ratledge, 1994). Consequently, the possible use of saprophytic mycobacteria, such as $M$. smegmatis, as model organisms to study iron metabolism in the pathogenic mycobacteria has been questioned, as the saprophytic mycobacteria were thought to elaborate only the hydrophilic siderophores, i.e. the true exochelins. The exochelins are peptide-based compounds (Sharman et al., $1995 \mathrm{a}, \mathrm{b})$, chemically unrelated to the carboxymycobactins. The occurrence of these latter molecules along with the exochelins would now reassert the usefulness of the saprophytic mycobacteria as models for studying iron uptake. Carboxymycobactins have also been recovered from culture filtrates of $M$. neoaurum grown iron-deficiently on glycerol/asparagine medium (Tan Eng
Lee \& C. Ratledge, unpublished work). Carboxymycobactins may therefore have a ubiquitous distribution throughout all those mycobacteria that produce mycobactin.

The reason why saprophytic mycobacteria produce two different siderophores is unclear: the relative importance of each is also difficult to assess, though the two siderophores appear to have different mechanisms for iron transport into the cell and so may respond to different environmental signals. Ferri-exochelin is taken up by an active, energy-dependent process whereas ferricarboxymycobactin is taken up by facilitated diffusion (Stephenson \& Ratledge, 1979, 1980). [This latter work was carried out using the carboxymycobactins, then still termed 'exochelins', from $M$. bovis BCG and $M$. intracellulare $(=M$. avium) before it was known that $M$. smegmatis produced similar materials.] The finding that exochelin synthesis precedes that of carboxymycobactin and mycobactin (Fig. 4) may suggest that exochelin is synthesized as the primary siderophore designed to acquire whatever iron may be readily available to the bacteria whereas carboxymycobactin may fulfil an ironscavenging role designed to remove final traces of iron from the environment and whose synthesis is triggered after the initial removal of iron by exochelin has ceased. However, mutants of $M$. smegmatis requiring exochelin for growth (Fiss et al., 1994) are still able to synthesize mycobactin and presumably, though this is not yet known, carboxymycobactin as well. Such mutants, though, do not grow without added exochelin, which would imply that either carboxymycobactin is not being formed or it is not fulfilling a metabolically useful function. Further work to clarify the role of carboxymycobactin in iron assimilation is clearly necessary, particularly as this appears to be the major if not sole route of iron sequestration and transport in the tubercle bacillus group, which appear not to produce the exochelins, though this must now be rigorously checked.

\section{ACKNOWLEDGEMENTS}

We are indebted to Glaxo (now Glaxo-Wellcome) Group Research Ltd for support of this work and to Dr S. J. Lane for helpful comments and advice.

\section{REFERENCES}

Fiss, E. H., Yu, S. Y. \& Jacobs, W. R. (1994). Identification of genes involved in the sequestration of iron in mycobacteria: the ferric exochelin biosynthetic and uptake pathways. Mol Microbiol 14, 557-569.

Gobin, J., Moore, C. H., Reeve, J. R., Wong, D. K., Gibson, B. W. \& Horwitz, M. A. (1995). Iron acquisition by Mycobacterium tuberculosis: isolation and characterization of a family of iron-binding exochelins. Proc Natl Acad Sci US A 92, 5189-5193.

Lane, S. J., Marshall, P. S., Upton, R. J., Ratledge, C. \& Ewing, M. (1995). Novel extracellular mycobactins, the carboxymycobactins from Mycobacterium avium. Tetrahedron Lett 36, 4129-4132.

Macham, L. P. \& Ratledge, C. (1975). A new group of water-soluble iron-binding compounds from mycobacteria : the exochelins. $J$ Gen Microbiol 89, 379-382. 
Macham, L. P., Ratledge, C. \& Nocton, J. C. (1975). Extracellular iron acquisition by mycobacteria: role of the exochelins and evidence against the participation of mycobactin. Infect Immun 12, 1242-1251.

Macham, L. P., Stephenson, M. C. \& Ratledge, C. (1977). Iron transport in Mycobacterium smegmatis: the isolation, purification and function of exochelin MS. J Gen Microbiol 101, 41-49.

Messenger, A. J. M. \& Ratledge, C. (1986). Siderophores. In Comprebensive Biotechnology, vol. 2, pp. 275-295. Edited by C. L. Cooney \& A. E. Humphrey. Oxford: Pergamon Press.

Ratledge, C. \& Hall, M. J. (1971). Influence of metal ions on the formation of mycobactin and salicylic acid in Mycobacterium smegmatis grown in static culture. J Bacteriol 108, 314-319.

Ratledge, C. \& Winder, F. G. (1962). The accumulation of salicylic acid by mycobacteria during growth on iron-deficient medium. Biochem J 84, 501-506.

Sharman, G. J., Williams, D. H., Ewing, D. F. \& Ratledge, C. (1995a). Isolation, purification and structure of exochelin MS, the extracellular siderophore from Mycobacterium smegmatis. Biochem J 305, 187-196.
Sharman, G. J., Williams, D. H., Ewing, D. F. \& Ratledge, C. (1995b). Determination of the structure of exochelin MN, the extracellular siderophore from Mycobacterium neoaurum. Chemistry $\mathcal{E}$ Biology 2, 553-561.

Snow, G. A. (1970). Mycobactins: iron-chelating growth factors from mycobacteria. Bacteriol Rev 34, 99-125.

Stephenson, M. C. \& Ratledge, C. (1979). Iron transport in Mycobacterium smegmatis: uptake of iron from ferriexochelin. $J$ Gen Microbiol 110, 193-202.

Stephenson, M. C. \& Ratledge, C. (1980). Specificity of exochelins for iron transport in three species of mycobacteria. J Gen Microbiol 116, 521-523.

Wheeler, P. R. \& Ratledge, C. (1994). Metabolism of Mycobacterium tuberculosis. In Tuberculosis: Pathogenesis, Protection, and Control, pp. 353-385. Edited by B. R. Bloom. Washington, DC: American Society for Microbiology.

Received 10 November 1995; revised 20 March 1996; accepted 27 March 1996. 